\title{
Paternidades a distancia: Malestares de padres separados de sus hijas e hijos tras la deportación
}

\section{Paternities at a distance: Discomforts of parents separated from their children}

Recibido el 3 de octubre de 2018. Aceptado el 25 de febrero de 2019 Publicado el 28 de febrero de 2019.

*Autor para correspondencia: Eduardo Torre Cantalapiedra. Correo electrónico: eduardotorrephd@gmail.com

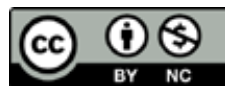

Esta obra está protegida bajo una Licencia Creative Commons Atribución-NoComercial 4.0 Internacional.
Eduardo Torre Cantalapiedra* (iD https://orcid.org/0000-0002-4074-3752

Maritza Rodríguez Gutiérrez ${ }^{\mathrm{b}}$ (D) https://orcid.org/0000-0001-5947-0224

a Instituto de Investigaciones Jurídicas, Universidad Nacional Autónoma de México, Ciudad de
México, México, correo electrónico: eduardotorrephd@gmail.com
b El Colegio de la Frontera Norte, Tijuana, México, correo electrónico: mrodriguezmep@colef.mx

Resumen

El objetivo de este trabajo es detectar y analizar los malestares que experimentan los padres al quedar separados de sus hijas/os tras ser deportados. Con base en cinco entrevistas a varones mexicanos deportados de Estados Unidos a la ciudad fronteriza de Tijuana, Baja California, exploramos los malestares que eventualmente experimentaron estos hombres por la separación física de sus hijas/os en relación con ser padres y con los mandatos de proveer y de ser afectivos con ellas/os. Adicionalmente, se reflexiona desde un plano principalmente teórico sobre los malestares de los hombres en la paternidad, especialmente, en el caso de las paternidades a distancia. Los padres entrevistados muestran malestares y otros padecimientos por no estar cerca de sus hijas/os para proveerles, cuidarles, disfrutar y establecer una relación de afecto con los mismos. Las conclusiones obtenidas, aunque preliminares, revelan rumbos para futuras investigaciones sobre paternidades y deportación.

Palabras clave: paternidades, migración internacional, deportación, malestares.

\section{Abstract}

The objective of this work is to detect and analyze the discomforts that parents experience when they are separated from their children after being deported. Based on five interviews of Mexican men deported from the United States to the border city of Tijuana, Baja California, we explored the discomforts that these men eventually experienced due to the physical separation of their children in relation to being parents and the mandates of providing and being emotional with them. Additionally, we reflect from a mainly theoretical perspective on the discomforts of men in fatherhood, especially in the case of paternities at a distan-

CÓMO CITAR: Torre Cantalapiedra, E. y Rodríguez Gutiérrez, M. (2019). Paternidades a distancia: Malestares de padres separados de sus hijas e hijos tras la deportación [Paternities at a distance: Discomforts of parents separated from their children]. Estudios Fronterizos, 20, e023. doi:https://doi.org/10.21670/ref.1902023 
ce. The parents interviewed showed discomfort and other illnesses because they were not close to their children to provide them, take care of them, enjoy themselves and establish an affectionate relationship with them. The conclusions obtained, although preliminary, reveal directions for future investigations on paternity and deportation.

Keywords: parenthood, international migration, deportation, discomforts.

\section{Introducción ${ }^{1}$}

Desde mediados de los años noventa se ha producido un auge en la cifra de deportaciones formales por parte de las autoridades estadounidenses, afectando de manera desproporcionada a los hombres mexicanos residentes en Estados Unidos (Dreby, 2012; Hagan, Eschbach y Rodríguez, 2008; Golash-Boza y HondagneuSotelo, 2013). Estas deportaciones han supuesto un incremento significativo en las separaciones familiares en un sentido espacial, ${ }^{2}$ al alejar cada año a decenas de miles de padres ${ }^{3}$ mexicanos, centroamericanos y de otros países, de sus esposas, hijas e hijos - quienes permanecen en territorio estadounidense- y han acarreado que un gran número de varones tengan que vivir sus paternidades a distancia, al menos de manera temporal.

La CEPAL ha definido la paternidad como la relación que los hombres establecen con sus hijas e hijos en el marco de una práctica compleja en la que intervienen factores sociales y culturales, que además se transforman a lo largo del ciclo de vida tanto del padre como de los hijos(as) (Ugalde, 2002, p. 5).

La literatura sobre migraciones y paternidades ha abordado el establecimiento y mantenimiento de esta vinculación padre-hijas/os a través de diversas prácticas bajo la circunstancia de una separación temporal del padre de sus vástagos, que puede devenir en permanente, etiquetando estas paternidades como "a distancia".

Muchos de los hombres deportados son padres de familia que han estado expuestos a diferentes formas de ser padre tanto en un sentido diacrónico - por los importantes cambios que se están produciendo en las paternidades y masculinidades en las últimas décadas- como sincrónico — las múltiples formas de ser padres que existen en

${ }^{1}$ Programa de Becas Posdoctorales en la Universidad Nacional Autónoma de México, Becario del Instituto de Investigaciones Jurídicas, asesorado por el doctor Enrique Mauricio Padrón Innamorato.

${ }^{2}$ Con "separación familiar", o simplemente separación, nos referimos a:

La separación física en la que se encuentran los miembros de la familia nuclear a ambos lados de una frontera internacional, lo que impide, o dificulta enormemente, que puedan mantener el contacto cara a cara. Por su parte, por "estar juntos", nos referiremos a la corresidencia - vivir bajo un mismo techo- o a la separación física de los miembros de la familia que no impide que estos [se] reúnan de manera relativamente sencilla y frecuente para interactuar cara a cara, por tanto, sin que se interpongan barreras administrativas ni que se tengan que soportar elevados costes económicos. Por lo que, a efectos de esta investigación, la disolución de la pareja — por ejemplo, por un divorcio- y la no corresidencia de los padres no implican necesariamente que estemos ante una separación familiar (Rodríguez Gutiérrez y Torre Cantalapiedra, s. f.).

${ }^{3}$ En este trabajo con los términos padres y paternidades nos estamos refiriendo exclusivamente a los padres varones y a las paternidades masculinas. 
México (roles más tradicionales) y en Estados Unidos (roles más modernos)—; por lo tanto, pueden encarar sus paternidades a distancia tras la deportación de muy diversas maneras.

Tanto la paternidad como la maternidad a distancia, se han estudiado principalmente en relación con diversos procesos migratorios voluntarios en los cuales los migrantes tienen un cierto grado de agencia en la toma de decisiones de movilidad, lo que se traduce en la configuración de familias transnacionales (Dreby, 2006; HondagneuSotelo y Avila, 1997; Parrella, 2007; Salazar, 2001, 2008; Zapata, 2009). Sin embargo, son escasos los trabajos que han abordado lo que sucede con las paternidades o las maternidades cuando el distanciamiento del padre o de la madre se produce a raíz de una migración forzada, como es el caso de una deportación. ${ }^{4}$ Asimismo, en estos trabajos queda reflejado el sufrimiento de las madres por la separación y la distancia de sus hijas/os, pero no del mismo modo el de los padres, quienes, por su condición de género, se considera que están mejor situados que sus parejas en homólogas circunstancias y que gozan de cierta inmunización al dolor que puede suponer la separación de sus hijas/os.

El objetivo de este trabajo es detectar y analizar los malestares que experimentan los padres de familia al quedar separados de sus hijas/os tras la deportación.

Retomamos la concepción de malestar expuesta por Tena y Jiménez (2014, p. 334) quienes señalan:

Que quien padece un malestar manifiesta una sensación de incomodidad o molestia dado su modo de ser, su espacio, situación o condición social, pero esta sensación es indefinible, es decir, es poco clara tanto como sensación como en cuanto a su magnitud y determinaciones. En este sentido quizá un malestar no llegue a considerarse dolor o disgusto ante una condición claramente identificada en el espacio y en el tiempo, e indica incluso la posibilidad de que a quien padece dicho malestar le sea difícil ponerlo en palabras pero aun así manifieste cierto grado de incomodidad ante ciertos hechos.

Para el logro del objetivo propuesto, el trabajo está dividido en tres secciones. Primero, se sitúa el auge del fenómeno de las paternidades a distancia tras la deportación en su contexto histórico: el apogeo de las políticas inmigratorias estadounidenses de control y deportación que se han centrado particularmente en hombres mexicanos, muchos de ellos padres cuyas familias se quedan en Estados Unidos. Segundo, se reflexiona de manera eminentemente teórica sobre cómo ser padre —en el sentido de práctica social más allá de lo meramente biológico- y los mandatos que se derivan de los modelos de paternidad preponderantes - tanto los tradicionales como alternativos o nuevos- pueden generar malestares en los varones, especialmente en el caso de quienes tienen que vivir sus paternidades a distancia. Tercero, con base en cinco entrevistas a profundidad a varones mexicanos deportados de Estados Unidos a la ciudad fronteriza de Tijuana, Baja California, México que quedaron separados de sus hijas/os se exploran los malestares que eventualmente experimentaron por tal situación de separación en relación con ser padres y con los mandatos de las paternidades de proveer y de ser afectivos con ellas/os. Las conclusiones obtenidas,

${ }^{4}$ Para la maternidad, véanse, por ejemplo, París Pombo y Peláez Rodríguez, 2015; Peláez Rodríguez y París Pombo, 2016; Peláez Rodríguez, 2016. 
aunque preliminares, revelan rumbos a seguir por futuras investigaciones sobre paternidades y deportación, que presentamos a modo de reflexiones finales.

\section{Deportación de varones y separación familiar}

La deportación es un instrumento disciplinario que implica que ciertas poblaciones sean etiquetadas como "deportables" - migrantes considerados "indeseables"- pese a sus conexiones y lazos afectivos con la sociedad de acogida (Peutz y De Genova, 2010). Según varios autores, el porqué de esta sujeción a un potencial proceso de deportación es la generación de mano de obra barata y dócil que puede ser empleada —explotada - cuando se requiera (De Genova, 2002). Asimismo, resulta fundamental escudriñar quiénes son los seleccionados para la deportación y qué efectos produce en sus vidas.

La información pública sobre las características de los inmigrantes indocumentados deportados de Estados Unidos es reveladora de la selectividad que este proceso tiene al enfocarse en la población masculina y mexicana. De acuerdo con datos en Simanski y Sapp (2013), en el año 2012, 89.3\% de los eventos de deportación formal correspondían a varones. Asimismo, según las estadísticas oficiales un porcentaje muy elevado de estos varones eran de origen mexicano, para el año 2015, 72\% de los eventos de deportación formal correspondían a migrantes procedentes de México (242 456 eventos; datos en United States Department of Homeland Security, 2016). ${ }^{5}$

Esta realidad se viene configurando desde años atrás, en 1986 la reforma de la ley de migración supuso la transformación del patrón migratorio de los mexicanos a Estados Unidos que pasó de caracterizarse por ser masculina y temporal a ser más familiar y tendente a la permanencia en aquel país (Massey, Pren y Durand, 2009; Torre Cantalapiedra y Giorguli, 2015). Este nuevo escenario migratorio se tradujo en separación familiar cuando miles de hombres mexicanos fueron deportados y quedaron separados de sus esposas e hijas/os —algunos de ellas/os ciudadanos de Estados Unidos-. ${ }^{6}$

Para el año 2016, aproximadamente uno de cada diez deportados mexicanos $(11.2 \%)$, en su gran mayoría varones, declaraba tener hijos menores de edad en Estados Unidos (Calva y Alarcón, 2018). Por lo tanto, estos padres separados de sus hijos tienen una gran motivación para emprender un nuevo viaje a Estados Unidos: la reunificación familiar; ${ }^{7}$ para su logro seguirán diversas estrategias tanto por vías legales como de cruce clandestino (Rodríguez Gutiérrez y Torre Cantalapiedra, s. f.).

\footnotetext{
${ }^{5}$ Además las políticas respecto a los inmigrantes indocumentados en Estados Unidos han tenido un carácter racista, en el sentido que en muchas ocasiones se han ejercido siguiendo prácticas de perfil racial (Torre Cantalapiedra, 2018). El perfil racial es una práctica policial ilegal consistente en que un agente del orden decida sobre su actuación de cumplimiento de la ley con base en la raza o la etnia de una persona.

${ }^{6}$ Cabe destacar, que la privación de libertad que los padres inmigrantes sufren por parte de las autoridades estadounidenses, en muchos casos por "delitos" relativos a su condición de inmigrantes, puede conducir a una separación de sus hijas/os, de mayor o menor duración. Esta separación resulta al menos tan perniciosa para las familias como la propia separación familiar que se produce tras la deportación.

${ }^{7}$ Se hace notar que la reunificación en México es descartada por muchas familias por diversas razones: el bienestar de los hijos, el deseo de que la reunificación se produzca en Estados Unidos, entre otros.
} 
Mariscal Nava y Torre Cantalapiedra (2018) consideran que las políticas antiinmigrantes de los diferentes niveles de gobierno en Estados Unidos - la militarización de la frontera, la criminalización del reingreso, las restricciones en el mercado laboral estadounidense, el auge de las deportaciones, entre otras-, junto con los elevados costos y riesgos del cruce clandestino constituirían importantes incentivos para que los inmigrantes mexicanos deportados opten o se vean forzados a quedarse en México. Los resultados de Rodríguez Gutiérrez y Torre Cantalapiedra (s. f.) apuntan a que el endurecimiento de las políticas migratorias de control en Estados Unidos ha provocado que se incremente el tiempo que los migrantes deportados permanecen separados de sus familias. Incluso para aquellos que tienen la intención de realizar el cruce de manera indocumentada, quienes ante el encarecimiento del cruce fronterizo — del pago a los coyotes - necesitan quedarse en México el tiempo necesario para recabar los recursos económicos necesarios para sufragar el nuevo viaje.

Dadas las dificultades para lograr la reunificación en Estados Unidos, muchos inmigrantes deportados, entre ellos los padres de familia, siguen la estrategia de establecerse en Tijuana para mantener la "cercanía" y vínculos con la familia, lo que posibilita y facilita las visitas de miembros que residen en Estados Unidos (París-Pombo y Peláez-Rodríguez, 2015; Rodríguez Gutiérrez, 2016; Ruiz, 2014; Rodríguez Gutiérrez y Torre Cantalapiedra, s. f.).

Por tanto, además de considerar los fenómenos de la separación familiar, las familias transnacionales y las paternidades a distancia tras la migración voluntaria, se debe tener en cuenta que los tres son también generados por la deportación. No solo las fuerzas de la globalización y otras relacionadas a esta colaboran en el engrosamiento del número de familias que "habitan" en el espacio transnacional, sino que, paradójicamente, también los Estados colaboran en tal fortalecimiento.

\section{Paternidades, migración y malestares}

\section{Nuevos modelos frente a tradicionales: Los mandatos de las paternidades y malestares}

Más allá de las definiciones, para un entendimiento más profundo del concepto de paternidad resulta conveniente partir de una serie de señalamientos que nos aproximen a sus múltiples aristas:

Primero, la paternidad, al igual que la maternidad, están construidas socialmente (Olavarría, 2001). Aunque más que de "paternidad", habría que hablar de "paternidades", ya que existen múltiples maneras en que los hombres se relacionan con sus hijas/os, las cuales han cambiado a lo largo del tiempo y presentan importantes diferencias tanto entre sociedades como al interior de estas (Bonino, 2003; De Keijzer, 1998; Gutmann, 1998). En un sentido analítico se puede hablar de modelos o referentes de paternidad, en la medida en que estas formas de relación paternofilial están dotadas de significados y sirven de guía a los hombres en su rol de padres.

Segundo, entre las masculinidades y las paternidades existen importantes implicaciones mutuas: a) los padres entienden sus paternidades desde su condición genérica, ocupando un lugar destacado, según los mandatos de la masculinidad 
hegemónica (retomando el concepto empleado por Connell, 2003). ${ }^{8}$ b) Un mandato fundamental de la masculinidad en la vida adulta, quizá el más importante, es tener hijos y ser padre. c) Los mandatos de la masculinidad se ven redefinidos desde el momento en que el varón se convierte en padre, hecho que resulta fundamental en la construcción personal de la identidad masculina.

Tercero, cada varón experimenta su paternidad de un modo distinto, adopta o se le imponen ciertos modelos de cómo "ser padre" y la ejerce de una cierta manera; todo ello va cambiando a lo largo de la vida. En todo este proceso de construcción de la propia paternidad resulta fundamental la figura paterna como referente que puede reproducirse en un cierto grado, pero también rechazarse. La repercusión de la paternidad para el hombre comienza incluso antes de tener hijas $/ \mathrm{os}^{9} \mathrm{y}$ después de tenerlos no termina sino hasta la muerte del varón.

De acuerdo con la amplia literatura sobre paternidades en América Latina tanto los referentes como el contenido y sus prácticas han cambiado de manera sustancial a lo largo de las últimas décadas. En este sentido, se hace énfasis en que los padres tradicionales ${ }^{10}$ están en declive en favor de los "nuevos padres" (Bonino, 2003). Este proceso de cambio promete progresos en las relaciones paternofiliales, pero no está exenta de desafíos para los varones:

Las nuevas generaciones de padres que ahora recrean la paradoja de intentar replantear el modelo tradicional de la paternidad, y dar paso a una paternidad sustentada en un ejercicio racional de la autoridad que genere relaciones familiares más placenteras y libres del peso de normas anticuadas que más provocan el distanciamiento entre los miembros del círculo familiar en vez de una proximidad basada en el afecto y el respeto por los demás (Montesinos, 2004, p. 198).

Para el análisis de estos procesos de cambio, varios autores recurren a la generación de tipologías de padres, en cambio en este trabajo consideramos que resulta operativo adoptar las siguientes dos propuestas analíticas: primero, entender las paternidades en términos de mandatos. Según Rebolledo (2008), las formas emergentes de ejercicio de la paternidad se pueden entender en relación con las modificaciones que hacen de los mandatos de la paternidad tradicional: desde los que hacen pequeños cambios a los mismos hasta los que aparecen como radicalmente opuestos a estos, pasando por aquellos que pretenden la renovación del poder patriarcal en decadencia. Segundo, tener en cuenta que las transformaciones de las paternidades están entrelazadas con los cambios en las identidades masculinas y en las relaciones de género (De Keijzer, 1998; Figueroa y Franzoni, 2011; Montesinos, 2004).

\footnotetext{
${ }^{8}$ Para el caso de México, siguiendo a De Keijzer (1997) podemos considerar que ha existido un modelo hegemónico de masculinidad como construcción cultural en donde el hombre queda representado como dominante en desmedro de la discriminación y subordinación tanto de las mujeres como de aquellos hombres que no encajen en el modelo.

${ }^{9}$ El siguiente fragmento del poema "Acerca de" ilustra la "paternidad por llegar" sobre la que reflexiona todo hombre a cierta edad: "Paternidad / ¿Algo que decir de mi hijo? /Que no ha nacido, / que es incorpóreo aún / y tal vez para siempre, / pero ahí está, / ya pensado, ya escrito" (Meneses, 2018, p. 63).

${ }^{10}$ Los padres en decadencia: el padre amo y el padre educador; y sus correlatos más actuales: el padre periférico y el padre ausente.
} 
En cuanto a la configuración de los modelos de paternidad en la actualidad, siguiendo la linea de los cambios introducidos sobre los modelos tradicionales, se quieren destacar dos cambios relevantes: 1) la caida del autoritarismo — que no de los aspectos positivos de la autoridad paterna- en favor la prominencia de aspectos como la crianza activa del padre y el vínculo afectivo-emocional entre padres e hijas/os y 2) el rol proveedor se mantiene, pero de un modo diferente.

Frente a la figura paterna tradicional, ahora cuestionada, el ejercicio de la paternidad para los "nuevos padres" supone una mayor participación de estos en la crianza de los hijos e hijas, y se fomenta especialmente el vínculo afectivo-emocional de los padres con sus hijas/os (Bonino, 2003; Montesinos, 2004). Así en una guía para los padres sobre la paternidad señala que:

Ser un padre activo y cuidar de tu hija/o es:

- Tener una relación afectuosa e incondicional con él o ella.

- Mantener una relación que vaya más allá de proveerle económicamente.

- Ser partícipe y actor del cuidado diario y la crianza de tu hijo/a con acciones como: cuidarle, alimentarle, hacerle dormir, vestirle, pasearle, enseñarle, etc.

- Promover un vínculo cariñoso, de apego mutuo, de cercanía afectiva con tu hijo/a.

- Compartir con la madre las tareas de cuidado de tu hijo/a y las tareas domésticas.

- Estar involucrado en todos los momentos del desarrollo de tu hijo o hija: embarazo, nacimiento, infancia temprana, niñez y adolescencia.

- Brindar una crianza respetuosa: cuidar, criar y educar con buen trato y mantener un clima de diálogo y respeto con la madre y la familia.

- Estimular el desarrollo de tu hijo/a: leyéndole cuentos, contándole historias, cantándole y/o poniéndole música, apoyándole en sus tareas escolares, jugando con él o ella (Aguayo y Kimelman, 2012, p. 2).

Como puede observarse, lo que se propone y promociona es una paternidad donde el vínculo afectivo padre-hijas/os y la participación en la crianza y las tareas de cuidado de las hijas e hijos resultan vitales. Sin embargo, coincidimos con Rebolledo (2008) en que la emergencia de nuevas formas de entender la paternidad no termina por desplazar todos los elementos de paternidad tradicional, según esta autora, existe en la actualidad una mezcla entre lo tradicional y lo moderno. El rol proveedor deja de ocupar el lugar central que tenía en las visiones más tradicionales de paternidades, sin que esto signifique que desaparezca como mandato fundamental de las paternidades, tanto en los discursos como en la práctica.

En cualquier caso, los cambios en las paternidades son sinónimo de que los hombres "se involucren en prácticamente todas las actividades, desde la proveeduría hasta el cuidado del hogar y los hijos, lo que en ocasiones genera algunas dificultades, malestares e incluso quejas en los hombres" [cursivas añadidas] (Salguero, Córdoba y Sapién, 2014, p. 458-459).

En la misma línea que estos autores, consideramos que es primordial dar cuenta de los malestares que los padres padecen. Muchas veces estos quedan ocultos por su condición de género en dos sentidos: primero, como varones los hombres deben ser fuertes y controlar sus emociones, negar, o al menos callar, el dolor y las pérdidas, entre otras. 
La construcción de la masculinidad no trata sólo de la generación de representaciones y prácticas sino también de una serie de presiones y límites en ciertas manifestaciones de la emotividad, sobre todo relativas al miedo, la tristeza y, frecuentemente, hasta la ternura (De Keijzer, 2003, p. 6).

Segundo, desde el poder y el privilegio patriarcal, lo masculino ha sido construido como lo opuesto a lo vulnerable, por lo que son escasas las investigaciones que buscan apreciar los sufrimientos que los hombres padecen.

Hay que tener en cuenta que "el reconocimiento subjetivo de un malestar requiere la identificación de un conflicto entre el deber ser social y el querer ser individual, lo cual no siempre es reconocido por ellos" (Tena y Jiménez, 2014, p. 335). La convivencia de varios modelos de paternidad que pueden y de hecho se convierten en referentes normativos de muchos padres de cómo ser "un buen padre", en estrecha relación con lo que significa "ser un hombre", pueden ser y son fuente de contradicción, confusión y conflictos. En efecto, la presencia de varios referentes y el carácter preceptivo de los mismos supone la existencia de una serie de mandatos, en ocasiones contradictorios entre sí, que los hombres deben acatar, o de lo contrario pueden presentarse malestares en las propias subjetividades de estos varones o en sus relaciones con los demás (mujeres y hombres).

Como veremos, ejercer las paternidades a distancia tras la deportación es un gran reto para los padres que la sufren, que puede derivar en malestares a los varones o inclusive afectar seriamente la salud mental de los mismos.

\section{Paternidades a distancia, mandatos y malestares}

Como se señaló anteriormente, las paternidades y maternidades a distancia surgen como resultado de procesos migratorios voluntarios e involuntarios. Los trabajos sobre paternidad a distancia realizados en diferentes geografías de origen y destino versan sobre casos en los que las familias tuvieron un cierto grado de agencia en las movilidades de sus miembros. Estos trabajos analizan cómo los vínculos de la paternidad se recrean a pesar de la separación espacial y de que sus miembros se encuentren a ambos lados de una frontera internacional; la mayoría dan primacía al análisis sobre la generación y el mantenimiento vínculo afectivo-emocional entre padres e hijas/os, pero también analizan el rol proveedor y las remesas económicas que los padres envían.

Zapata (2009) destaca el hecho de que los padres y madres colombianos desarrollan estrategias para mantener los lazos afectivos con sus hijas/os a pesar de la distancia, asegurando su presencia emocional, aunque estén en la distancia. Con este fin los padres y madres utilizan las remesas sociales (llamadas, contacto por internet, etc.) y las remesas monetarias para suavizar los cambios que se producen por estar ellos ausentes (Zapata, 2009).

Salazar (2008), para el caso de Filipinas, al mismo tiempo que constata que con la migración los padres transnacionales filipinos reproducen y refuerzan los roles tradicionales de la paternidad en aquel país: ser la autoridad, imponer disciplina a sus hijas/os y cumplir con el rol proveedor — como pilares de la casa—, destaca la existencia de una brecha ( $g a p$ ) emocional entre padres filipinos y sus hijas/os - entrevista a estos últimos-, en el sentido que los hijas/os sienten un malestar e incomodidad en relación con sus padres migrantes; asimismo, refiere a la dificultad de los hijos de comunicarse abiertamente con sus padres. 
En el caso de México, la migración por motivos económicos ha permitido a los hombres mexicanos (de diferente orígenes y estratos sociales) reforzar - recuperar en muchos casos - su papel como proveedores cumpliendo los mandatos de la masculinidad hegemónica y de la paternidad (Dreby, 2006; Hondagneu-Sotelo y Avila, 1997; Rosas, 2007). De acuerdo con Hondagneu-Sotelo y Avila (1997) cuando los hombres llegan al norte y dejan a sus familias en México lo hacen —como lo hacían en el pasado- en cumplimiento de su obligación familiar de proveer. Además, los padres han podido posponer su cercanía frente a sus hijas/os sin sentirse dolidos ni acusados por ello (Bonino, 2003). Mientras que las mujeres migrantes tienen que cargar con el estigma — se les acusa de abandonar a sus hijos, entre otras-, la culpa y la crítica de los otros cuando dejan atrás a sus familias (Hondagneu-Sotelo y Avila, 1997).

Dreby (2006) analiza y compara la forma en que madres y padres mexicanos en Estados Unidos viven separados de sus hijas/os. En primer lugar, destaca las similitudes entre ambos. Tanto madres como padres utilizan las llamadas telefónicas para manejar las relaciones con sus hijos, ambos brindan soporte económicos y regalos a sus hijos a través de remesas. Sin embargo, en relación con el rol proveedor que México atribuye a los varones, Dreby (2006) encuentra que los padres que son exitosos en el cumplimiento de la proveeduría son los que tienden a mantener relaciones estables y regulares de contacto con sus hijas/os independientemente de la situación marital. Mientras que la relaciones entre madre e hijas/os tiene más que ver con la habilidad de las madres de demostrar intimidad emocional desde la distancia con independencia del su papel en la proveeduría.

Pese a que no recuperan la experiencia de los varones, resulta conveniente traer a colación algunos hallazgos en París-Pombo y Peláez-Rodríguez (2015), PeláezRodríguez y París-Pombo (2016) y Peláez-Rodríguez (2016) sobre las experiencias de madres mexicanas deportadas a la ciudad de Tijuana que quedaron separadas de sus hijas/o, donde las autoras encontraron que las mujeres entrevistadas experimentaron la deportación con sentimientos de profunda tristeza y dolor en cuanto a la lejanía de las hijas/os y además sin tener la posibilidad de resignificar sus maternidades con el envío de remesas - cosa que sí pueden hacer las madres mexicanas que migran buscando unas mejores condiciones de vida para sus hijas/os-.

Por tanto, estos trabajos abordan con detalle cuestiones que pueden entenderse como correlato a dos mandatos fundamentales de los nuevos padres: el de proveer condición necesaria pero no suficiente para ser "buenos padres"-, y, sobre todo, con el mandato de establecer y mantener una óptima relación afectivo-emocional con las hijas e hijos. Consideramos que tanto ser padre a distancia como el incumplimiento de estos dos mandatos puede provocar malestares a los varones, al surgir contradicciones y conflictos entre el ejercicio de la paternidad deseado, el efectivamente practicado (que en muchas ocasiones está moldeado por factores estructurales sobre los cuales el padre en cuestión no tiene ningún control: en este caso la separación tras la deportación) y las exigencias de los mandatos de los modelos de paternidades preponderantes.

Aunque los textos sobre paternidad a distancia no pretenden expresamente analizar los malestares que los padres experimentan en relación con tener que vivir su paternidad a distancia, a partir de estos trabajos podemos realizar algunas reflexiones. Salazar (2008) da cuenta del malestar que los hijos padecen en la relación con sus padres en la distancia, la existencia de la brecha emocional así lo atestigua. De la misma forma podemos esperar que algunos padres también sufran por no poder mantener una relación afectivo-emocional cercana con sus hijas/os. El distanciamiento emocional 
o incluso ruptura del vínculo afectivo paterno-filial que encuentra Dreby (2006), puede ser resultado de los malestares que genera en los padres el incumplimiento del mandato de proveer, que han sido analizado en diversas circunstancias como fuente de conflictos para los hombres (Jiménez y Tena, 2007; Torre Cantalapiedra y Rodríguez de Jesús, 2018). Por su parte, el texto de Peláez-Rodríguez y París-Pombo (2016) trata de manera explícita el sufrimiento que las mujeres deportadas padecen al quedar separadas de sus hijas/os por el distanciamiento y por la dificultad o imposibilidad de encontrar cierto alivio a través de la proveeduría.

En el caso de las paternidades a distancia tras la deportación, es posible que se conjuguen malestares similares a los casos en los que la separación es voluntaria, sin embargo, consideramos que tiene elementos que pueden agravar los malestares de los padres:

1) La familia no ha decido voluntariamente la separación. Se trata de una separación familiar forzada e inesperada que no es discutida en el seno del hogar (Peláez-Rodríguez y París-Pombo, 2016). 2) Al no ser una separación voluntaria, puede no haber una preparación para la misma. Esto puede provocar que la integridad psicológica de los miembros de la familia pueda verse más fácilmente afectada. 3) Existen mayores trabas para las visitas familiares (en ocasiones, pueden tornarse imposibles), por ejemplo, las prohibiciones de reentrar que conllevan muchos de los procesos de deportación, pueden tener un importante efecto disuasorio. 4) Implican separaciones más duraderas, que incluso pueden llegar a convertirse en permanentes (Rodríguez Gutiérrez y Torre Cantalapiedra, s. f.). 5) Cumplir con el rol proveedor es más complejo desde sociedades de origen donde los salarios son bajos y el desempleo elevado.

\section{Análisis exploratorio de los malestares de padres deportados y que quedan separados de sus hijas/os}

Antes de proceder al análisis de los malestares, presentamos a continuación cómo se desarrollaron las entrevistas y las características de los entrevistados y sus familias. En este apartado, con base en cinco entrevistas semiestructuradas realizadas a varones mexicanos deportados por las autoridades estadounidenses, se analizan los malestares que presentan por la separación de sus hijas/os. ${ }^{11}$ En las entrevistas, se les preguntó por sus experiencias migratorias e historias familiares, antes y después de la deportación, y sobre sus proyectos migratorios y familiares futuros.

$\mathrm{Al}$ no estar contemplados expresamente, los hallazgos sobre los malestares de los varones en sus experiencias de paternidad a distancia se pueden calificar de serendípicos. Se puede decir que la cuestión de los malestares surge en las conversaciones como resultado de la generación de empatía y confianza entrevistadorentrevistado al plantear la entrevista como una distendida conversación evitando la dinámica pregunta-respuesta de los cuestionarios, y fruto de la necesidad de los hombres entrevistados de expresar sus emociones, quizás reprimidas con familiares y amigos, pero "confesables" ante personas desconocidas. Ya sea que muchas veces para su captación se deba "leer entre líneas".

Esta forma de indagar sobre los malestares tiene como ventaja principal que está

${ }^{11}$ A cada persona se le entrevistó en una sola ocasión. La duración de las entrevistas varió entre los 30 y 80 minutos. 
libre del sesgo de ser respuestas inducidas por los temas de interés del investigador; por el contrario, tiene la desventaja de que los datos cualitativos así obtenidos no permiten examinar todos los aspectos de interés en cada caso. En suma, consideramos que los datos empíricos empleados son de gran interés para un análisis preliminar como el que aquí se presenta.

Las características sociodemográficas de los varones entrevistados y de las familias que se quedan en Estados Unidos favorecen los objetivos exploratorios de este trabajo. La selección de los entrevistados incluyó a padres de familia que quedaron separados de sus familias (esposa o exesposa e hijas/hijos) tras la deportación, de haber residido en aquel país por al menos 18 años. En la Tabla 1 se muestran características seleccionadas de los entrevistados y de sus familias al momento de producirse la última deportación (algunos de los entrevistados sufrieron más de una deportación).

Las cinco familias de los entrevistados contaban con estatus migratorio mixto, en todas ellas había al menos un hijo nacido en Estados Unidos (o en un caso, estaban esperando el nacimiento de su primer hijo) y al menos el padre era inmigrante indocumentado o residente permanente legal (estatus que perdió tras su primera deportación). Los entrevistados fueron deportados entre 2002 y 2017; años de auge de las políticas antiinmigrantes de control migratorio y de deportación (Torre Cantalapiedra, 2018; Rodríguez Gutiérrez y Torre Cantalapiedra, s. f.).

Los cinco migrantes fueron deportados con edades comprendidas entre los 20 y 57 años, cuando llevaban viviendo en Estados Unidos entre 18 y 51 años; lo que apunta a un fuerte arraigo en aquel país. Antes de su deportación, cuatro de ellos vivían en el estado de California y uno de ellos en Illinois. Esto implica que nuestros entrevistados han estado en contacto con una gran diversidad de formas de paternidad, los referentes prevalecientes en la sociedad estadounidense y los referentes, en principio más tradicionales, de la sociedad mexicana, ya sea, en algunos casos, exclusivamente a través de la figura de sus padres mexicanos.

\section{El comienzo de la paternidad}

Fernando es un joven de 20 años que llevaba prácticamente toda su vida (18 años) en Estados Unidos, cuando fue deportado por las autoridades estadounidenses por cargos que eran exclusivamente relativos a su estatus migratorio indocumentado. Al momento de ser deportado su esposa, ciudadana de Estados Unidos, estaba embarazada de siete meses de la que sería su primera hija. Ella le fue a visitar en una sola ocasión a Tijuana, donde Fernando decidió establecerse, pero ella no pudo visitarlo con frecuencia debido al coste económico que conlleva. Son varios los malestares que derivan de esta situación en relación con la paternidad que él quiere ejercer y la paternidad a distancia a la que se verá "forzado". 
Tabla 1. Características seleccionadas de los cinco entrevistados y de sus familias ${ }^{12}$

\begin{tabular}{|c|c|c|c|c|c|c|}
\hline & $\begin{array}{l}\text { Edad padre } \\
\text { al momento } \\
\text { de la última } \\
\text { deportación }\end{array}$ & $\begin{array}{c}\text { Estatus legal al } \\
\text { momento de la } \\
\text { última depor- } \\
\text { tación }\end{array}$ & $\begin{array}{c}\text { Tiempo de } \\
\text { residencia } \\
\text { en Estados } \\
\text { Unidos }\end{array}$ & $\begin{array}{l}\text { Tiempo de } \\
\text { residencia en } \\
\text { México tras la } \\
\text { deportación }\end{array}$ & $\begin{array}{l}\text { Hijas e } \\
\text { hijos }\end{array}$ & $\begin{array}{c}\text { Edad hijos } \\
\text { al momento } \\
\text { última depor- } \\
\text { tación }\end{array}$ \\
\hline Fernando & 20 años & $\begin{array}{c}\text { Inmigrante } \\
\text { indocumentado }\end{array}$ & 18 años & 2 semanas & $\begin{array}{c}\text { Esposa } \\
\text { embarazada }\end{array}$ & No procede \\
\hline Josué & 32 años & $\begin{array}{c}\text { Inmigrante } \\
\text { indocumentado }\end{array}$ & 25 años & 7 años & Hija & 3 años \\
\hline \multirow{5}{*}{ Antonio } & \multirow{5}{*}{36 años } & \multirow{5}{*}{$\begin{array}{c}\text { Inmigrante } \\
\text { indocumentado }\end{array}$} & \multirow{5}{*}{21 años } & \multirow{5}{*}{4 años } & Hijo & 14 años \\
\hline & & & & & Hija & 13 años \\
\hline & & & & & Hija & 12 años \\
\hline & & & & & Hija & 8 años \\
\hline & & & & & Hija & 5 años \\
\hline \multirow{4}{*}{ Samuel } & \multirow{4}{*}{37 años } & \multirow{4}{*}{$\begin{array}{l}\text { Residente per- } \\
\text { manente legal }\end{array}$} & \multirow{4}{*}{31 años } & \multirow{4}{*}{14 años } & Hijo & 13 años \\
\hline & & & & & Hijo & 7 años \\
\hline & & & & & Hija & 6 años \\
\hline & & & & & $\begin{array}{l}\text { Hija } \\
\text { (finada) }\end{array}$ & No procede \\
\hline \multirow{3}{*}{ Diego } & \multirow{3}{*}{57 años } & \multirow{3}{*}{$\begin{array}{c}\text { Inmigrante } \\
\text { indocumentado }\end{array}$} & \multirow{3}{*}{51 años } & \multirow{3}{*}{3 años } & Hija & 33 años \\
\hline & & & & & Hijo & 35 años \\
\hline & & & & & Hijastra & 31 años \\
\hline
\end{tabular}

Fuente: Elaboración propia con base en las entrevistas realizadas en 2016 y 2017.

Notas: Mantienen relación de pareja con el primer cónyuge con el que tuvieron hijas/os. Algunos de los entrevistados rehicieron su vida con otra persona. Se incluyen los hijos de los entrevistados, aunque fueran con más de una pareja. Adicionalmente, un migrante deportado fue separado de su esposa embarazada de siete meses.

En primer lugar, Fernando querría ver nacer a su hija, pero asume que es algo que se va a perder. Dado que su esposa tendrá a su hija en Estados Unidos y la reunificación familiar en México quedaría descartada, las vías de las que dispone tanto legales como clandestinas no le conducirían al territorio estadounidense antes de que ella hubiese dado a luz. Las reunificaciones en Estados Unidos, acudiendo a las vías legales de ingreso resultan por lo general muy lentas y con demasiadas incertidumbres, mientras que la "vías indocumentadas" si bien son relativamente rápidas, requieren de recursos económicos para hacer uso de los servicios de los coyotes, y, además, estas maneras clandestinas pueden acarrear consecuencias dañinas en el futuro (por ejemplo, penas de privación de libertad) (Rodríguez Gutiérrez y Torre Cantalapiedra, s. f.).

En segundo lugar, Fernando quiere estar cerca de su hija en Estados Unidos para cuidar de ella, tanto por los valores que le inculcó su padre (ser responsable de sus

${ }^{12}$ Los nombres utilizados son ficticios para preservar la confidencialidad. 
descendientes), así como su propia experiencia vital le hacía indeseable no estar en estos momentos con su esposa e hija:

A mí lo que me importa es estar con mi esposa y mi hija porque tanto tiempo estaba yo solo, mis papás se fueron a Fresno cuando yo tenía 17 años, tanto tiempo yo estuve solo, uno necesita de mamá o papá, yo tenía que arreglármelas para pagar la renta para pagar mi comida y siento que es mi responsabilidad [...] cuidar a mi esposa y mi hija. De que ella puede trabajar después de tener a mi niña, puede... ella puede porque es fuerte, pero yo no quiero. Mi papá me enseñó que si vas a tener un hijo asumas la responsabilidad, porque los niños no tienen la culpa en este mundo de nada. So, lo que quiero es cuidar a mi hija (Fernando, 2017 [20 años de edad, trabajador de centro de llamadas]).

Como se puede apreciar, Fernando entiende su rol como padre y hombre en un sentido tradicional, puesto que él no quiere que su esposa trabaje, sino ser él quien cumpla con el rol proveedor, mandato esencial de la masculinidad hegemónica (Rosas, 2007; Torre Cantalapiedra y Rodríguez de Jesús, 2018). Con su salario como trabajador en un centro de llamadas, le sería muy dificultoso sufragar el coste de la vida de una niña recién nacida y de su esposa en Estados Unidos. La necesidad del ejercicio del rol paterno en ese sentido le hace plantearse el cruce indocumentado y desoír el consejo de su tía en cuanto a cómo proceder para regresar a territorio estadounidense:

Yo sé que si no puedo verla nacer está bien, pero yo quiero estar en su vida. Mi tía me dice... - Me deportaron por cinco años—, y dice "quédate los cinco años, después pides un acta de perdón y que tu esposa te pida, y regresas con una visa" (Fernando, 2017).

\section{Malestares psicológicos, vínculos afectivo-emocionales y pérdidas}

Tras un cuarto de siglo en Estados Unidos, Josué fue deportado cuando tenía 32 años, lo que se tradujo en una separación familiar que precipitó la disolución conyugal. La combinación de la separación física y el fin del vínculo conyugal puede ser nefasta para la relación de este padre con su hija de tres años. Los vínculos padre-hijas/os no se extinguen con la disolución; ya que como señala Ugalde (2002), son "directos" e "independientes" de los arreglos establecidos entre los progenitores. Sin embargo, de facto las disoluciones conyugales pueden derivar en la obstrucción y eliminación del rol paterno (Zicavo y Fuentealba, 2012). En este caso ambos progenitores observaron la separación familiar tras la deportación como algo incluso positivo:

Ahh, mi ex[esposa] como que estaba ya, porque teníamos unos problemas entonces, como que estaba ¿aliviada? ¿happy? Not happy, ¿relieved? yo creo, de que no tenía los problemas conmigo, entonces, bueno ni tanto porque ahora ya estamos separados pero también a lo mejor, maybe she felt relieved, maybe, yo creo, hasta me dijo: "ya los billes [las facturas] de electricidad me salieron más cortos" [se ríe] pero she felt maybe relieved porque sí teníamos, we had some issues... [...], y ya también ella en ese tiempo me dijo que ya no quería nada, so... (Josué, 2016 [39 años, activista]). 
Asimismo, a pesar de la distancia y el fin de la relación entre los padres, la exesposa de Josué le visitaba con la niña con relativa frecuencia "dos veces al mes unas ocasiones, una vez cada dos meses en otras" y ambos cónyuges han mantenido una relación cordial. Ella ha querido que él forme parte de la vida de la hija. Esto no implica la ausencia de malestares, al preguntarle sobre su intención de reunificación familiar con su hija en Estados Unidos, Josué nos "confiesa" que se siente culpable por no haber considerado la vía indocumentada como la manera de intentar la reunificación familiar y estar con su hija y considera que ha perdido la oportunidad de establecer una relación afectiva más estrecha con ella:

...a veces me siento culpable por qué tanta gente que ya se ha ido, dije: "ya estuviera allá”, $[\ldots]$ se perdió mucho de la relación, tiempo, mi niña está más grande, son los mejores tiempos de los chiquillos, pues cuando están chiquillos y pues se acuerdan de su papá, que esto que $1[0]$ otro... (Josué, 2016).

Samuel pasó más de tres décadas en Estados Unidos, la deportación le separó de sus tres hijos — con dos diferentes parejas, relaciones que acabaron disueltas y de manera conflictiva- cuando estaban en su niñez o adolescencia temprana (de 13, 7 y 6 años al momento de la deportación). Su experiencia migratoria en Estados Unidos estuvo marcada por el abuso del alcohol; lo que le condujo al encarcelamiento, a la deportación y a la prohibición de su reingreso de por vida al territorio estadounidense. La situación de separación de su familia le generó un considerable malestar emocional e incluso depresión, por lo que durante un tiempo no quiso ponerse en contacto con ninguno de sus tres hijos:

Emocionalmente no sabía que decirles o estaba muy depressed o [es] taba tomando para quitar este, este dolor que... le dije: 'pues como puede ser, si yo estuve... si yo fui soldado', '¿cómo pude tener... este gobierno puede separarme de mi familia?’ ya, dije: 'ya cumplí el tiempo ¿Qué les voy a decir a mis hijos?' O... es como... el tiempo se te va, el tiempo se te va, porque dice[s]: 'es como si estuviera en otro mundo'... y sí te importa, pero no te importa... y no puedes hacer nada de eso, y cada vez que te acercas a la pared, pinche pared, parece que crece... crece un pie... I hate to go there, ¿close to the Wall... da un sentimiento... me entiendes?.. yo a veces le digo: 'Dios ¿por qué no mandas fuego de lluvia nomás de la barda pa'llá?' [se ríe]... (Samuel, 2016 [52 años, desempleado]).

Aunque con el paso de los años Samuel supera esta situación y recupera un cierto grado de comunicación con sus hijos, se puede considerar el análisis de su vivencia de separación familiar tras una deportación sine die desde la perspectiva del concepto de "pérdida ambigua". De acuerdo con Falicov (2002, párr. 10) que sigue a Pauline Boss, la pérdida ambigua se da en la migración cuando "la gente y los lugares están físicamente ausentes, y al mismo tiempo, están agudamente presentes en la mente del inmigrante". A diferencia de la pérdida de un familiar debido a un fallecimiento que es cierta y tiene rituales para superarla, la pérdida de una paternidad cercana, del vínculo afectivo-emocional, es ambigua y no definitiva, en cuanto que siempre se puede considerar, aunque en ocasiones sea muy improbable, una futura reunificación con las hijas/os en México o en Estados Unidos, además esta carece de rituales estandarizados para superarla. 
Al igual que señala Falicov (2002), las visitas que los migrantes realizan a sus familiares sirven para hacer más llevadera la pérdida. En este caso las visitas que le hace su hijo mayor en México y el contacto con sus otros dos hijos a través de llamadas telefónicas e Internet pueden servirle para sobrellevar la situación.

Samuel quiso interrumpir la entrevista para compartir unos versos. $\mathrm{Al}$ analizar los mismos pudimos dar cuenta de que contenía elementos de reflexión sobre su propia experiencia, de expresión de sus propias emociones, ¿son estas líneas escritas una manera de hacer catarsis y de lidiar con una pérdida ambigua?

\section{The heart of mine}

My mind is strong,
because all the struggles I had in my life
I'm not weak anymore
You can't hurt me, because I have control
Y dominio propio sobre mis emociones
Yes, I know my children are long gone,
No contact, can't see them
Don't care anymore, they're gone alive
And distance it's a difference
So long, four or five, was that a long time?
Can't remember, don't care anymore
Still love them, but can't touch anymore
Heart I had, it sure covers it
(Samuel, 2016 [fragmento del poema]).

Estos versos muestran algunas contradicciones que es importante analizar. Primero, a los hombres los mandatos de la masculinidad hegemónica les exigen que tengan control sobre sus emociones y que no las expresen. De ahí la importancia de afirmar la invulnerabilidad, el control y el dominio de sus emociones: "You can't hurt me, because I have control / Y dominio propio sobre mis emociones"; que quedaron desbocadas tras la deportación cuando todavía era débil, pero ya no lo es más: "I'm not weak anymore". Y niega que le importen la distancia, no verlos, el tiempo y la imposibilidad del contacto físico con sus hijos "No contact, can't see them / Don't care anymore, they're gone alive / And distance it's a difference / So long, four or five, was that a long time? / Can't remember, don't care anymore". Sin embargo, al mismo tiempo se puede apreciar el reconocimiento de sus emociones y sentimientos como su amor por ellos y autocompasión: "Still love them, but can't touch anymore". Segundo, se reconoce que sus hijos se han ido: "Yes, I know my children are long gone", pero que se han ido vivos "they're gone alive". Lo que puede ser una constatación de que algo se ha perdido, pero no del todo, una suerte de aceptación de una pérdida ambigua. 


\section{Sobrellevando la paternidad a distancia tras la deportación}

Uno los padres entrevistados sobrellevaba la deportación entre la resignación y la aceptación. En este sentido, la manera en que manejan su paternidad al quedar separados de sus hijas/os tras la deportación no resulta muy diferente de las separaciones familiares a raíz de la migración.

Antonio tenía más de dos décadas viviendo en Estados Unidos cuando una simple parada de tráfico desembocó en una deportación y quedar separado de su esposa y sus cinco hijos (todos ellos menores de 14 años al momento de la deportación). Ambos progenitores coinciden en que su reunificación en México es peor opción que la separación familiar:

Ella no quiere venirse para acá, yo tampoco quiero que se venga ella... porque pues este...los...mis niños ¿iverdad? Mis niños, ella, no quiero desincomodarlos y pues son cinco... o sea, para estar cómodo yo voy a desincomodar a ellos, pues no como que no sería justo, $[\ldots]$ yo no quisiera traérmelos, porque una: no son de aquí, no hablan el idioma, no están acostumbrados y ellos aquí vendrían a, yo los puedo hacer mexicanos ¿vea? Pero estarían entrando como ilegal, o sea, ya no estarían en su país, entonces mejor que estén allá... (Antonio, 2016 [36 años, trabaja en un taller mecánico]).

Tanto la esposa como los hijos son ciudadanos de Estados Unidos, por lo que pueden cruzar la frontera sin problemas. Como sucede con muchos migrantes, visitan al papá en las vacaciones de verano y en las de invierno. Como se puede apreciar es una situación similar a la de las paternidades a distancia por la migración, solo que, en este caso, son su esposa e hijas/os quienes viajan a México para reunirse con él en las festividades. Asimismo, Antonio mantiene la comunicación con sus familiares a través de llamadas telefónicas y videollamadas.

\section{La paternidad a distancia en adultos-mayores con hijos adultos}

Diego fue deportado por segunda vez con 57 años, tras más de medio siglo de vida en Estados Unidos, donde quedaron su hija, su hijo y su hijastra, de dos matrimonios, que ya superaron los treinta años, y sus nueve nietos. La relación con su segunda esposa se extinguió tras la deportación, puesto que ella no piensa regresar a México.

Me bloqueó de Facebook, todo, no quería saber nada y me envió un mensaje y me dijo: 'que te vaya muy bien, te deseo lo mejor, si a lo mejor regresas... nos podemos juntar, siempre te voy a querer, pero pues ahorita necesito que estés aquí y no estás, y tengo que salir adelante (Diego, 2016 [57 años, trabajador en un centro de llamadas]).

En ningún momento sintió la imperiosa necesidad de volver a estar con su familia en Estados Unidos o los malestares y problemas que se observaron en el resto de los casos en relación con el ejercicio de la paternidad. Esto posiblemente se debe a que su forma de entender la paternidad implica que cuando sus hijas/os son mayores, y ya no se requiere de cumplir con el rol proveedor, el hombre no necesariamente tiene que tener un contacto tan asiduo y afectivo con sus vástagos. En cualquier caso, sí ha 
procurado mantener el vínculo afectivo con su hija, hijastra e hijo a través de llamadas telefónicas.

\section{Reflexiones finales}

Las madres y las hijas/os no son las únicos que sufren a causa de las deportaciones, los hombres también lo hacen. Al tratar temas personales — como la relación afectiva entre padres e hijas/os con varones que quedaron separados de sus familias tras una deportación-, surgen de manera espontánea expresiones sobre los malestares que esta situación está trayendo a sus vidas.

Los malestares externados por los entrevistados en relación con la paternidad y sus mandatos son varios. En particular cuando las hijas/os tienen corta edad, los padres sienten malestares por no estar cerca de ellos para proveerles, cuidarles, disfrutar y establecer una relación de afecto con los mismos. Algunos de los entrevistados parecen sobrellevar la situación de separación familiar de una manera relativamente sencilla, posiblemente por el carácter de estos para lidiar con las presiones sociales en cuanto a su rol como padres y la manera en que entienden el ejercicio de sus paternidades en el momento de sus vidas en que fueron deportados. Asimismo, en el caso de Antonio y otros de los entrevistados, mantener la comunicación y las visitas periódicas de los familiares en México sirven para sobrellevar la situación de separación.

El concepto de malestar, si bien ha resultado útil para poder examinar una parte del sufrimiento de los varones "hilando fino" y buscando aquello que puede quedar oculto, dado el mandato de la masculinidad hegemónica de no expresar emociones, resulta insuficiente para analizar los casos de los padres entrevistados. Esto se debe a que la experiencia de ser padre a distancia, debido a una deportación, resulta en situaciones traumáticas que causan sufrimiento y enfermedad más allá de la esfera de los malestares. Por tanto, futuros análisis deberán adoptar conceptos que analicen estos problemas que sufren los padres deportados separados de sus hijas/os. Así, por ejemplo, los malestares psicológicos que padecen estos varones en relación con su paternidad a distancia y que pueden constituir problemas de salud mental de gravedad, podrían analizarse como pérdidas que se experimentan de diversas maneras.

Asimismo, cada vez más hombres son capaces de externar sus emociones sin encapsularlas y ocultarlas en conceptos más suaves o eufemísticos. Pese a los tópicos, el caso de Samuel muestra que la separación de los hijos después de la deportación puede tener consecuencias tan emocionalmente desgarradoras para los varones como en el caso de las mujeres. Futuras investigaciones podrán analizar en un sentido más amplio que el de este trabajo, las diferentes emociones que los varones experimentan en los procesos como el de la separación familias después de la deportación.

Las grandes dificultades para retornar a territorio estadounidense supeditan la posibilidad de tener contacto cara a cara con sus hijas e hijos a que puedan visitarles en México. Asimismo, cuando los hijos son menores, las visitas dependen de las decisiones de sus esposas y exesposas. En el caso de los migrantes deportados a los que se les prohíbe de por vida pisar territorio estadounidense, la distancia con las hijas/ os adquiere un significado terrible, que pocas veces se produce cuando la migración es voluntaria. 
Se puede observar que la separación familiar tras la deportación del padre produce situaciones conyugales que van desde el conflicto hasta todo lo contrario. Futuras investigaciones podrán profundizar en las conexiones entre las separaciones familiares y las disoluciones conyugales, y cómo estos factores pueden impactar conjuntamente en el ejercicio de la paternidad y en desarrollo de malestares.

La edad de los padres y de los hijos y las generaciones están asociadas a ciertas formas de entender, ejercer las paternidades y están relacionados con diferentes exigencias sociales para los padres, que son relevantes a la hora de entender los malestares de los migrantes deportados. Por ejemplo, la diferencia de edades entre Fernando (20) y Diego (57), y las de sus hijos al momento de la deportación, nos hablan de momentos de la paternidad que suelen significarse de manera completamente diferente. Asimismo, Fernando pertenece a una generación donde se exige un involucramiento integral a los padres. Aunque estas asociaciones no deben entenderse en un sentido determinista, el diseño de futuras investigaciones sobre paternidades a distancia se puede beneficiarse de tenerlos en cuenta.

Finalmente, futuros trabajos deberán profundizar en lo que implica el hecho de que las paternidades a distancia sean a raíz de una deportación y no a consecuencia de migraciones voluntariamente decididas por las familias.

\section{Agradecimientos}

Los autores agradecen a Juan Guillermo Figueroa Perea y a Dulce María Mariscal Nava por su lectura y comentarios a una versión previa de este trabajo. Agradecimiento que extendemos a la labor de los dictaminadores anónimos.

\section{Referencias}

Aguayo, F. y Kimelman, E. (2012). Guía para promover paternidad activa y la corresponsabilidad en el cuidado y la crianza de niños y niñas. Recuperado de http://www.codajic.org/sites/www.codajic.org/files/2012-11-27\%20Guia\%20Paternidad\%20 Activa\% 20alta.pdf

Bonino, L. (2003). Las nuevas paternidades. Cuadernos de Trabajo Social, 16, 171-182. Recuperado de http://revistas.ucm.es/index.php/CUTS/article/view/CUTS0303110171A/7735

Calva, L. E. y Alarcón, R. (2018). Migrantes mexicanos deportados y sus planes para reingresar a Estados Unidos al inicio del gobierno de Donald Trump. Revista Mexicana de Ciencias Políticas y Sociales, LXIII(233), 43-68.

Connell, R. (2003). Masculinidades. México: Universidad Nacional Autónoma de México-Programa Universitario de Estudios de Género.

De Genova, N. P. (2002). Migrant "Illegality" and Deportability in Everyday Life. Annual Review of Anthropology, 31(1), 419-447.

De Keijzer, B. (1997). El varón como factor de riesgo: Masculinidad, salud mental y salud reproductiva. En E. Tuñón (Coord.), Género y salud en el sureste de México (pp. 67-81). Villa Hermosa: Ecosur, UJAD. 
De Keijzer, B. (1998). Paternidad y transición de género. En B. Schmukler (Coord.), Familias y relaciones de género en transformación. Cambios transcendentales en América Latina y El Caribe (pp. 301-325). México: Population Council.

De Keijzer, B. (2003). Hasta donde el cuerpo aguante: Género, cuerpo y salud masculina. Recuperado de http://unpan1.un.org/intradoc/groups/public/documents/ icap/unpan045504.pdf

Dreby, J. (2006). Honor and virtue: Mexican parenting in the transnational context. Gender E Society, 20(1), 32-59. doi: https://doi.org/10.1177\%2F0891243205282660

Dreby, J. (2012). The Burden of Deportation on Children in Mexican Immigrant Families. Journal of Marriage and Family, 74(4), 829-845. doi: 10.1111/j.17413737.2012.00989.x

Falicov, C. J. (2002). Migración, pérdida ambigua y rituales. Perspectivas Sistémicas, (69). Recuperado de http://www.redsistemica.com.ar/migracion2.htm

Figueroa, J. G. y Franzoni, J. (2011). Del hombre proveedor al hombre emocional: Construyendo nuevos significados de la masculinidad entre varones mexicanos. En F. Aguayo y M. Sadler (eds.), Masculinidades y políticas públicas. Involucrando hombres en la equidad de género (pp. 64-81). Santiago, Chile: Universidad de Chile-Facultad de Ciencias Sociales.

Golash-Boza, T. M. y Hondagneu-Sotelo, P. (2013). Latino Immigrant Men and the Deportation Crisis: A Gendered Racial Removal Program. Latino Studies, 11(3), 271-292. doi: https://doi.org/10.1057/1st.2013.14

Gutmann, M. C. (1998). Machos que no tienen ni madre: La paternidad y la masculinidad en la ciudad de México. Revista de Estudios de Género, La Ventana, 1(7), 118-163.

Hagan, J., Eschbach, K. y Rodríguez, N. (2008). U.S. Deportation Policy, Family Separation, and Circular Migration. International Migration Review, 42(1). Recuperado de http://www.jstor.org/stable/27645716

Hondagneu-Sotelo, P. y Avila, E. (1997). "I'm Here, but I'm There": The Meanings of Latina Transnational Motherhood. Gender and Society, 11(5), 548-571. Recuperado de https://www.jstor.org/stable/190339

Jiménez, M. L. y Tena, O. (2007). Algunos malestares de varones mexicanos ante el desempleo y el deterioro laboral. Estudio de caso. En M. Burín, M. L. Jiménez e I. Meler (Comps.), Precariedad laboral y crisis de la masculinidad: Impacto sobre las relaciones de género (pp. 148-173). Buenos Aires, Argentina: Universidad de Ciencias Empresariales y Sociales.

Mariscal Nava, D. M. y Torre Cantalapiedra, E. (2018). Cinco elementos clave para entender la (re)inserción laboral de los migrantes retornados en México en el último decenio. Ser Migrante oIM, (5), 24-37.

Massey, D. S., Pren, K. y Durand, J. (2009). Nuevos escenarios de la migración México-Estados Unidos. Las consecuencias de la guerra antiinmigrante. Papeles de Población, 15(61), 101-128. Recuperado de http://www.redalyc.org/articulo. oa?id=11211806006

Meneses, M. A. (2018). Acerca de. El Comité 1973. Dossier 36, Migraciones y movilidades humanas en la Contemporaneidad. Recuperado de https://issuu.com/revistaelcomite1973/docs/el_comit_36_migraciones.-versi_n_f 
Montesinos, R. (2004). La nueva paternidad: Expresión de la transformación masculina. Polis: Investigación y Análisis Sociopolítico y Psicosocial, 2(4), 197-220. Recuperado de http:/ /www.redalyc.org/pdf/726/72620409.pdf

Olavarría, J. (2001). ¿Hombres a la deriva? Poder, trabajo y sexo. Recuperado de https://biblio.flacsoandes.edu.ec/catalog/resGet.php?resId=53415

París-Pombo, M. D. y Peláez-Rodríguez, D. C. (2015). Far from Home: Mexican Women Deported from the US to Tijuana, Mexico. Journal of Borderlands Studies, 551-561.

Parrella, S. (2007). Los vínculos afectivos y de cuidado en las familias transnacionales. Migrantes ecuatorianos y peruanos en España. Migraciones Internacionales, 4(2), 151-188. Recuperado de http://www.scielo.org.mx/pdf/migra/v4n2/v4n2a6. pdf

Peláez-Rodríguez, D. C. (2016). Stuck on This Side: Symbolic Dislocation of Motherhood due to Forced Family Separation in Mexican Women Deported to Tijuana. The Journal of the Society for Philosophy in the Contemporary World, 23(1), 5-21.

Peláez-Rodríguez, D. C. y París-Pombo, M. D. (2016). Deportación femenina y separación familiar: Experiencias de mexicanas deportadas a Tijuana. En E. Levine, S. Nuñez y M. Verea (Coords.), Nuevas experiencias de la migración de retorno (pp. 59-80). México: Universidad Nacional Autónoma de México, Centro de Investigaciones sobre América del Norte, Instituto Matías Romero, Secretaría de Relaciones Exteriores.

Peutz, N. y De Genova, N. (2010). Introduction. En N. De Genova y N. Peutz (Eds.), The Deportation Regime: Sovereignty, Space, and the Freedom of Movement (pp. 1-29). Durham: Duke University Press.

Rebolledo, L. (2008). Del padre ausente al padre próximo. Emergencias de nuevas formas de paternidad en el Chile actual. En K. Araujo y M. Prieto (Eds.), Estudios sobre sexualidades en América Latina (pp. 123-140). Quito, Ecuador: Flacso.

Rodríguez Gutiérrez, M. (2016). Reconfiguración de la vida familiar de mexicanos residentes de Estados Unidos deportados entre 2008-2015 (Tesis de maestría). El Colegio de la frontera Norte, Tijuana, México.

Rodríguez Gutiérrez, M. y Torre Cantalapiedra, E. (s. f.). Camino a la reunificación: Análisis de las estrategias migratorias de familias mexicanas tras la separación por deportación.

Rosas, C. (2007). Migrar para proveer, Cardaleños, desde Veracruz a Chicago: un estudio de caso. En M. L. Jiménez y O. Tena (Coords.), Reflexiones sobre masculinidades y empleo (pp. 473-506). Recuperado de http://biblioteca.clacso.edu.ar/ Mexico/crim-unam/20100428124919/Masculyempleo.pdf

Ruiz, O. T. (2014). Undocumented Families in Times of Deportation at the San Diego-Tijuana Border. Journal of Borderlands Studies, 29(4), 391-403.

Salazar, R. (2001). Mothering from a Distance: Emotions, Gender, and Intergenerational Relations in Filipino Transnational Families. Feminist Studies, 27(2), 361-390. Recuperado de http://www.jstor.org/stable/3178765? origin=crossref\&seq=1\#page_scan_tab_contents

Salazar, R. (2008). Transnational Fathering: Gendered Conflicts, Distant Disciplining and Emotional Gaps. Journal of Ethnic and Migrations Studies, 34(7), 1057-1072. doi: https://doi.org/10.1080/13691830802230356 
Salguero, A., Córdoba, D. y Sapién, S. (2014). Dificultades, malestares y quejas de algunos hombres sobre su paternidad. Revista Electrónica de Psicología Iztacala, 17(2). Recuperado de http://www.revistas.unam.mx/index.php/repi/article/ view/46997/42312

Simanski, J. y Sapp, L. M. (2013). Immigration Enforcement Actions: 2012. Recuperado de https://www.dhs.gov/sites/default/files/publications/Enforcement_Actions_2012.pdf

Tena, O. y Jiménez, M. L. (2014). Algunos malestares en la experiencia de los varones: ¿Podemos ir reflexionando sobre sus derechos reproductivos? En J. G. Figueroa Perea y A. Salguero (Coords.), ¿Y si hablas de...sde tu ser hombre? Violencia, paternidad, homoerotismo y envejecimiento en la experiencia de algunos varones (pp. 331-358). México: El Colegio de México.

Torre Cantalapiedra, E. (2018). La estrategia de attrition through enforcement: Políticas antiinmigrantes de Arizona y sus efectos sobre las familias mexicanas. Norteamérica. Revista Académica del CISAN-UNAM, 13(1), 169-192. doi: http://dx.doi. org/10.20999/nam.2018.a006

Torre Cantalapiedra, E. y Giorguli, S. E. (2015). Las movilidades interna y de retorno de los varones migrantes mexicanos a Estados Unidos en perspectiva longitudinal (1942-2011). Estudios Demográficos y Urbanos, 30(1), 7-43. Recuperado de http:/ / estudiosdemograficosyurbanos.colmex.mx/index.php/edu/article/ view/1484/1477

Torre Cantalapiedra, E. y Rodríguez de Jesús, C. (2018). Migración y masculinidades: Análisis de la experiencia de un joven que emigró por amor. Desacatos. Revista de Ciencias Sociales, (56), 140-157. Recuperado de_http://desacatos.ciesas.edu.mx/ index.php/Desacatos/article/view/1882

Ugalde, Y. (2002). Propuesta de indicadores de masculinidad. Recuperado de https://repositorio.cepal.org/bitstream/handle/11362/25583/1/LCmexL542_es.pdf

United States Department of Homeland Security, Office of Immigration Statistics. (2016). 2015 Yearbook of Immigration Statistics. Recuperado de https://www.dhs. gov/sites/default/files/publications/Yearbook_Immigration_Statistics_2015. pdf

Zapata, A. (2009). Familia transnacional y remesas: Padres y madres migrantes. Revista Latinoamericana de Ciencias Sociales, Niñez y Juventud, 7(2), 1749-1769. Recuperado de http://www.redalyc.org/pdf/773/77314999024.pdf

Zicavo, N. y Fuentealba, A. (2012). Resignificando la paternidad, crianza y masculinidad en padres post divorcio. Revista de Investigación en Psicología, 15(2), 115-127. doi: http://dx.doi.org/10.15381/rinvp.v15i2.3693

\section{Entrevistas}

Antonio. (30 de marzo de 2016). Entrevista de M. Rodríguez [audio]. Tijuana. Diego. (11 de marzo de 2016). Entrevista de M. Rodríguez [audio]. Tijuana. Fernando. (15 de junio de 2017). Entrevista de D. Mariscal [audio]. Tijuana. Josué. (14 de marzo de 2016). Entrevista de M. Rodríguez [audio]. Tijuana. Samuel. (31 de marzo de 2016). Entrevista de M. Rodríguez [audio]. Tijuana. 
Eduardo Torre Cantalapiedra

Mexicano. Doctor en Estudios de Población por El Colegio de México. Actualmente, es Investigador Postdoctoral en el Instituto de Investigaciones Jurídicas de la Universidad Nacional Autónoma de México (UnAm). Pertenece al Sistema Nacional de Investigadores (Nivel 1). Líneas de investigación: migración internacional y políticas migratorias. Entre sus publicaciones recientes destacan: Movilidades internas e internacionales en Colombia: determinantes, patrones migratorios y diversidad de destinos, 1950-2010, Revista Latinoamericana de Estudios de Población (RELAP), 10(19), 2017 en coautoría con Silvia E. Giorguli.

\section{Maritza Rodríguez Gutiérrez}

Mexicana. Obtuvo el grado de Maestra en Estudios de Población por el Colegio de la Frontera Norte (2016) con la tesis "Reconfiguración de la vida familiar de mexicanos residentes de Estados Unidos deportados entre 2008-2015”. Egresada del Programa de Licenciatura en Economía por la Universidad Autónoma de Ciudad Juárez (2013). Líneas de investigación: migración internacional y fenómenos transnacionales derivadas de la migración México-Estados Unidos, especialmente separación familiar causada por la deportación. 